\title{
Treatment of methicillin-resistant Staphylococcus aureus in Latin America
}

\begin{abstract}
The global spread of methicillin-resistant Staphylococcus aureus (MRSA) means it is now a pathogen of worldwide public health concern. Within Latin America, MRSA is highly prevalent, with the proportion of $S$. aureus isolates that are methicillin-resistant on the rise, yet resources for managing the infection are limited. While several guidelines exist for the treatment of MRSA infections, many are written for the North American or European setting and need adaptation for use in Latin America. In this article, we aim to emphasize the importance of appropriate treatment of MRSA in the healthcare and community settings of Latin America. We present a summary of the available guidelines and antibiotics, and discuss particular considerations for clinicians treating MRSA in Latin America.
\end{abstract}

Keywords: MRSA, treatment, antibiotic therapy, Latin America.

\section{INTRODUCTION}

Guidelines available for the treatment for methicillin-resistant Staphylococcus aureus (MRSA) include those listed in Table 1. ${ }^{1-10}$

While European and American guidelines provide an excellent reference point for the treatment of MRSA infections, treatment must be guided by local factors, including likely sources of infection, and risk factors associated with the patient population or patient environment. Up-todate epidemiological data on the local incidence of pathogens and resistant strains are needed to guide the choice of initial (empiric) antibiotic therapy; ${ }^{11}$ accurate microbiological diagnosis and susceptibility testing facilitates the selection of appropriate definitive antibiotic therapy. The availability of resources, including availability of antibiotics and microbiological testing, is also an important consideration. Such local restrictions in Latin America may be similar to those discussed by the Asian HAP working group, ${ }^{3}$ where drug availability, formulary restrictions in individual hospitals and cost of treatment are important considerations in addition to clinical factors.
In Latin America, resources for microbiology may be limited, especially in hospitals outside of the large cities, and collaboration with a reference laboratory may be necessary to obtain data for choosing the most effective antibiotic against the locally-circulating MRSA clones.

Inappropriate choice of antibiotic therapy is costly for several reasons. Firstly, and most importantly, it is associated with increased morbidity and mortality (Figure 1)..$^{12,13}$ Secondly, extra drugs are used unnecessarily and perhaps for a longer period of time due to inefficacy. Thirdly, it may lead to increasing rates of resistance. Therefore, it is imperative that antibiotics are used in a rational manner, with the goals of improving patient outcomes and minimizing the selection for antimicrobial resistance. The rational use of antibiotics requires an understanding of the principles of antibiotic therapy, taking account of microbiological and clinical data, de-escalation of primary therapy based on culture and susceptibility testing, as well as clinical outcomes..$^{11,14}$ Antibiotics need to be used at the optimal dose and via an appropriate route of administration to achieve penetration to the site of infection. A
Authors

Carlos M. Luna Eduardo RodríguezNoriega $^{2}$

Luis Bavestrello Eduardo Gotuzzo ${ }^{4}$ on behalf of the Latin American Working Group on Gram

Positive Resistance.

${ }^{1}$ Department of Internal Medicine, Pulmonary Diseases Division, Hospital de Clínicas, Universidad de Buenos Aires, Argentina.

${ }^{2}$ Hospital Civil de Guadalajara, Fray Antonio Alcalde, Instituto de

Patología Infecciosa y Experimental, Centro Universitario Ciencias de la Salud, Universidad de Guadalajara, Jalisco,

Mexico.

${ }^{3}$ Clinica Reñaca, Viña Del Mar, Chile.

${ }^{4}$ Universidad Peruana Cayetano Heredia, Lima, Peru.

Correspondence to:

Carlos M. Luna

Professor of

Medicine and

Pulmonary Medicine Department of Internal Medicine,

Pulmonary Diseases Division

Hospital de Clínicas, Universidad de

Buenos Aires

Arenales 2557, $1^{\circ} \mathrm{A}$

Buenos Aires (1425),

Argentina

Phone:

+54-9-11-57561535

Fax:

+54-11-59508931

E-mail: cymluna@

fmed.uba.ar 
Table 1. Guidelines available for the treatment for MRSA

\begin{tabular}{|c|c|}
\hline Organization & Infection \\
\hline $\begin{array}{l}\text { American Thoracic Society } \\
\text { and Infectious Diseases } \\
\text { Society of America }\end{array}$ & $\begin{array}{l}\text { Hospital-acquired pneumonia } \\
\text { (HAP), ventilator-associated } \\
\text { pneumonia (VAP) and } \\
\text { healthcare-associated } \\
\text { pneumonia (HCAP) in adults }{ }^{1}\end{array}$ \\
\hline $\begin{array}{l}\text { Latin American Thoracic } \\
\text { Society }\end{array}$ & $\begin{array}{l}\text { Nosocomial pneumonia in } \\
\text { Latin America }^{2}\end{array}$ \\
\hline Asian HAP Working Group & HAP in Asia $^{3}$ \\
\hline $\begin{array}{l}\text { American Thoracic Society } \\
\text { and Infectious Diseases } \\
\text { Society of America }\end{array}$ & $\begin{array}{l}\text { Community-acquired } \\
\text { pneumonia (CAP) }\end{array}$ \\
\hline $\begin{array}{l}\text { Infectious Diseases Society of } \\
\text { America }\end{array}$ & $\begin{array}{l}\text { Skin and soft tissue infections } \\
(\mathrm{SSTI})^{5}\end{array}$ \\
\hline $\begin{array}{l}\text { Infectious Diseases Society of } \\
\text { America }\end{array}$ & $\begin{array}{l}\text { Intravascular catheter-related } \\
\text { infections }{ }^{6}\end{array}$ \\
\hline $\begin{array}{l}\text { Fundación del Centro de } \\
\text { Estudios Infectológicos } \\
\text { (FUNCEI), Argentina }\end{array}$ & $\begin{array}{l}\text { Bone and joint infections } \\
\text { caused by methicillin-resistant } \\
\text { staphylococci }^{63}\end{array}$ \\
\hline $\begin{array}{l}\text { Joint Working Party of } \\
\text { the British Society for } \\
\text { Antimicrobial Chemotherapy, } \\
\text { Hospital Infection Society } \\
\text { and Infection Control Nurses } \\
\text { Association }\end{array}$ & $\begin{array}{l}\text { Nosocomial and community- } \\
\text { acquired MRSA infections }{ }^{8}\end{array}$ \\
\hline $\begin{array}{l}\text { British Society for } \\
\text { Antimicrobial Chemotherapy } \\
\text { Working Party on Community- } \\
\text { onset MRSA Infections }\end{array}$ & MRSA in the community ${ }^{9}$ \\
\hline $\begin{array}{l}\text { Healthcare Infection Control } \\
\text { Practices Advisory Committee } \\
\text { in the USA }\end{array}$ & $\begin{array}{l}\text { MRSA; multidrug resistant } \\
\text { infections in healthcare } \\
\text { settings }^{10}\end{array}$ \\
\hline $\begin{array}{l}\text { The Pan-American Health } \\
\text { Organization (PAHO) } \\
\text { guidelines }\end{array}$ & $\begin{array}{l}\text { MRSA in Pan-American } \\
\text { regions (www.paho.org) }\end{array}$ \\
\hline
\end{tabular}

combination of antibiotics should also be used where necessary.

Setting national and local policies to restrict antibiotic availability and encourage appropriate use in the healthcare setting and in the community requires multidisciplinary collaboration. Implementation must include education of healthcare professionals and the public, as well as monitoring, to ensure adherence. ${ }^{15}$

\section{OVERVIEW OF ANTIBIOTICS WITH ACTIVITY AGAINST MRSA}

The current arsenal of antibiotics available for the treatment of MRSA includes only one topical agent, a limited number of oral agents (two of which can also be delivered intrave-
Figure 1: Inadequate antibiotic treatment is associated with an increased risk of mortality in critically ill patients

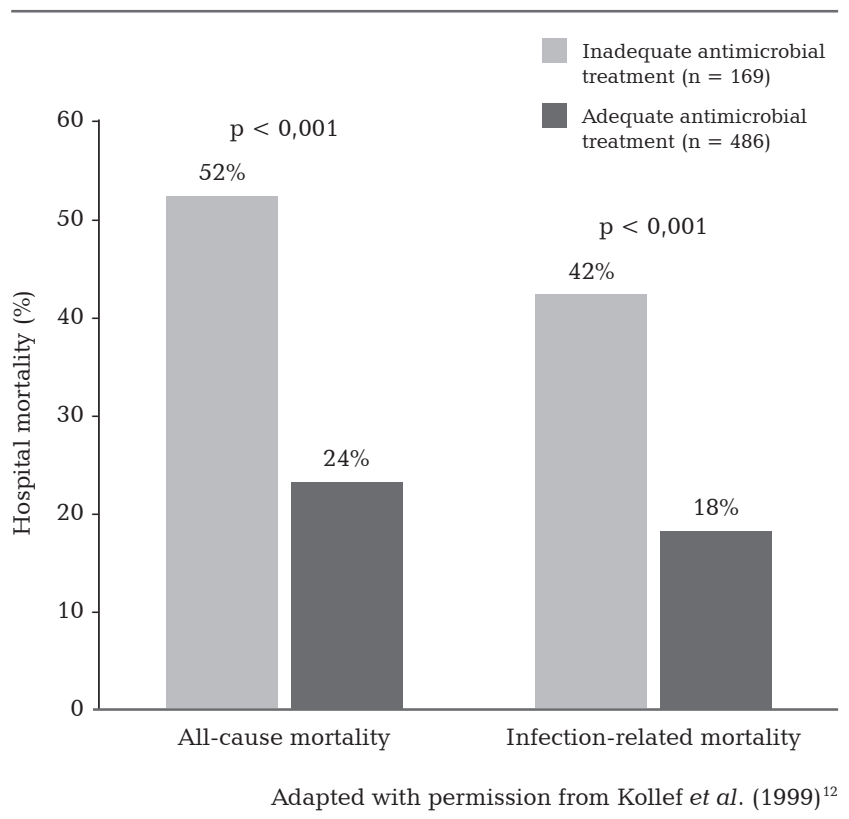

nously) and several agents which are only available for intravenous (IV) infusion. The following section provides comment on these agents, their mechanisms of actions, and their utility for treatment of MRSA infection. Sader et al. report on patterns of antibiotic resistance among Gram-positive bacterial isolates collected from bloodstream, and skin and soft tissue infections (SSTIs) in Latin American hospitals between 2003 and 2008. ${ }^{16}$

\section{Topical agents}

Mupirocin was originally approved as a topical agent used to treat impetigo due to $S$. aureus and S. pyogenes, but is also commonly used to treat other SSTIs, as well as postoperative wound infections. ${ }^{17,18}$ Mupirocin acts by inhibiting bacterial protein and ribonucleic acid (RNA) synthesis. While effective against mild community-associated SSTI, prolonged and intense use of mupirocin (including for decolonization purposes) has resulted in certain MRSA strains developing resistance to this antibiotic. ${ }^{18}$

\section{Oral agents}

Oral therapies commonly used in the treatment of MRSA include the agents tetracycline and rifampin (in combination therapy), as well as clindamycin, linezolid and trimethoprim-sulfamethoxazole (TMP-SMX; although its use is restricted in some countries). Clindamycin and linezolid are available in both oral and IV formulations, and are discussed in the section below.

The two components in TMP-SMX combination therapy inhibit successive steps in the folate biosynthesis pathway. 
This antibacterial agent has regained popularity because of its activity against community-associated MRSA (CA-MRSA) isolates, ${ }^{19-21}$ although more clinical data are needed to fully evaluate its efficacy and safety. ${ }^{22}$

Tetracyclines act by inhibiting bacterial protein synthesis. The good oral bioavailability and tissue penetration of this class of drug (which includes the extended-spectrum doxycycline and minocycline) make them an option for outpatient treatment of MRSA infections. ${ }^{23}$

If rifampin is used for the treatment of MRSA infections, it is usually in combination therapy, as one limitation of rifampin monotherapy is the development of resistance. ${ }^{24}$ The authors of a systematic review on rifampin adjunctive therapy concluded that this is most promising for osteomyelitis and prosthetic device-related infections, but that further clinical data are needed. ${ }^{25}$

\section{Oral and intravenous agents}

Clindamycin and linezolid are available in both oral and IV formulations. Clindamycin is often chosen as the initial or definitive treatment for community-acquired SSTI for several reasons: it exhibits $90 \%$ bioavailability after oral administration and penetrates into the skin and skin structures; is active in spite of a high bacterial burden at the infection site; and may inhibit the production of virulence factors in MRSA. ${ }^{26-28}$ Clindamycin acts by inhibiting bacterial ribosomal translocation, and hence, protein synthesis. However, MRSA can develop resistance to clindamycin as a result of methylase production, which modifies the binding sites for macrolides, lincosamides and streptogramins (MLS mechanism), and results in ribosomal target modification. Resistance to clindamycin can be induced by the presence of other antibiotics and is not recognized using standard susceptibility methods. In vitro, the induction of clindamycin resistance by erythromycin can be reliably detected by placement of an erythromycin disk in close proximity to a clindamycin disk, and observing the effects of the presence of erythromycin on the clindamycin halo. ${ }^{29,30}$

Linezolid, an oxazolidinone antibiotic, is indicated for the treatment of MRSA in nosocomial pneumonia and complicated SSTI infections, including diabetic foot infections, without concomitant osteomyelitis. It inhibits the initiation of bacterial protein synthesis at the $50 \mathrm{~S}$ ribosome. ${ }^{31}$ The novel mechanism of action of this compound means that crossresistance to other antibiotics is unlikely. ${ }^{32}$ Linezolid can be administered either IV or orally, and therapy can be readily switched between these administration routes without dose adjustment. It exhibits $100 \%$ bioavailability following oral administration $^{32}$ and excellent penetration into well-perfused tissues, including the lung and other soft tissues. ${ }^{33}$ In addition, linezolid can be used without dose adjustments in patients with mild-to-moderate renal impairment. ${ }^{32}$

\section{Intravenous agents}

Vancomycin has been the cornerstone of treatment for MRSA infections for many years. Although its frequent use has resulted in the global emergence of MRSA strains with reduced susceptibility to this antibiotic, vancomycin is still considered to be effective against MRSA in Latin America.

Vancomycin is a glycopeptide and acts by inhibiting cell wall synthesis. An increase in the prevalence of MRSA in both nosocomial and community infections led to a vast increase in vancomycin use, ${ }^{34}$ and as a result, MRSA strains began developing resistance mechanisms. In 1996, S. aureus isolates with intermediate resistance to vancomycin (VISA) were first identified in an isolate from a patient in Japan who received multiple and prolonged courses of vancomycin. ${ }^{35}$ In 1997 and 1999, VISA isolates were also recovered from patients in the US who had been exposed to extended treatment with vancomycin (25 days to 18 weeks). ${ }^{36,37}$

S. aureus can also develop full resistance to vancomycin (VRSA), which occurs through the acquisition of resistance genes (van A) from vancomycin-resistant enterococci. ${ }^{38,39}$ The evolution of resistance to vancomycin has been associated with a polymorphism in the accessory gene regulator (agr), and studies have found a high rate of treatment failure with vancomycin in infections due to MRSA with the agr type II polymorphism. ${ }^{40}$ However, there is currently no evidence that MRSA isolates with reduced susceptibility to vancomycin are of clinical significance in Latin America. Major risk factors for vancomycin resistance include prior vancomycin exposure within 30 days of the MRSA culture collection, and stay in an intensive care unit (ICU) where vancomycin is used. ${ }^{41}$

In addition to concerns about developing resistance, the efficacy of vancomycin may also be limited by poor tissue penetration (particularly in the lung), slow bactericidal effect and toxicity. ${ }^{42}$ Therefore, appropriate use of vancomycin must include measurements of its serum levels to ensure adequate activity and avoid toxicity, as well as tests for antimicrobial susceptibility to prevent the development of resistance. ${ }^{43}$

Teicoplanin is another glycopeptide antibiotic, structurally related to vancomycin, which is an alternative for the treatment of Gram-positive infections, including MRSA; it has been evaluated in endocarditis, osteomyelitis and septic arthritis. ${ }^{44}$ Potential advantages of teicoplanin over vancomycin include a longer half-life, less nephrotoxicity and reduced requirement to monitor serum levels. Also unlike vancomycin, teicoplanin does not appear to cause anaphylactoid reactions related to histamine release. ${ }^{45}$

Tigecycline is a broad-spectrum glycylcycline antibiotic with activity against Gram-positive pathogens, including MRSA. ${ }^{46}$ Tigecycline binds to the 30 S ribosomal subunit, inhibiting protein synthesis (and hence bacterial growth). Tigecycline overcomes mechanisms of resistance seen with 
tetracyclines, including drug-specific efflux pumps and ribosomal protection. ${ }^{7}$ CA-MRSA strains isolated from SSTI infections, including isolates that carry Panton-Valentine leukocidin (PVL) genes, are often susceptible to tigecycline. ${ }^{47}$ While this compound has excellent tissue distribution properties, including reaching high concentrations in the colon and the lung, it reaches lower concentrations in the serum..$^{48}$

Daptomycin is a cyclic lipopeptide with a unique mechanism of action. It preferentially binds and inserts into Grampositive bacterial membranes, where it causes rapid membrane depolarization, and hence, bacterial cell death. ${ }^{49}$ The bactericidal effects of daptomycin make this antibiotic useful for the treatment of MRSA infections, including SSTI, bacteremia and right-sided endocarditis. ${ }^{49,50}$ Limitations of daptomycin include the fact that it can only be given intravenously and inactivation of the drug by lung surfactant, thereby preventing its use in pneumonia. ${ }^{51}$

Quinupristin-dalfopristin (Q-D), a combination of two streptogramins, shows activity against Gram-positive bacteria, including MRSA. ${ }^{52,53}$ Use of this antibiotic is reserved for unresponsive infections and patients intolerant to the initial therapy. ${ }^{53}$ Infusion-related side-effects contribute to poor tolerability. This, combined with drug-drug interactions (particularly with agents cleared through the cytochrome $\mathrm{P}_{450}[3 \mathrm{~A} 4]$ system $\left.^{54}\right)$, limits the usefulness of this antibiotic. ${ }^{55}$

\section{ANTIBIOTIC TREATMENT OF COMMON HEALTHCARE-ACQUIRED MRSA INFECTIONS}

\section{Pneumonia (HAP/VAP)}

MRSA is a potential pathogen for the various pneumonias acquired within a hospital and healthcare setting, and the choice of initial empiric therapy should consider MRSA as a possible etiologic agent. ${ }^{1}$ Healthcare-related pneumonias can be categorized as hospital-acquired pneumonia (HAP; pneumonia occurring $\geq 48$ hours after admission), ventilator-associated pneumonia (VAP; arising $>$ 48-72 hours after endotracheal intubation), and healthcare-associated pneumonia (HCAP; defined as pneumonia arising in patients fulfilling any of the following conditions: hospitalized within 90 days of infection; residing in a nursing home or long-term care facility; recent IV delivery of antibiotic therapy; chemotherapy; wound care; or attendance at a hospital or hemodialysis clinic ${ }^{1}$ ).

Non-VAP, non-ICU HAP is an important cause of hospital morbidity, observed most frequently in medical wards and in elderly patients with severe underlying diseases. There are very few published studies on the etiology of this subset of HAP. However, potential multidrug resistant (MDR) pathogens, together with the common etiologic agents for community-acquired pneumonia (CAP), should be considered. ${ }^{1,56}$ MRSA should be considered in patients at risk for resistant pathogens or in those meeting the criteria of severity at clinical presentation. ${ }^{57}$
MRSA is a common pathogen in VAP and should be considered in those patients with late-onset VAP, use of prior antimicrobial therapy, or any other condition associated with the presence of resistant pathogens. ${ }^{1}$ As MRSA is also associated with HCAP, the initial empiric regimen should include coverage of MRSA. A summary of guidelines for the management of adults with HAP and VAP is listed in Table 2. ${ }^{1}$

Delay in the initiation of appropriate antibiotic therapy for patients with HAP is associated with increased mortality. ${ }^{1,2}$ Selection of initial empiric therapy is based on risk factors for specific pathogens, modified as appropriate using knowledge of local patterns of antibiotic resistance/organism prevalence, ${ }^{1,3}$ as well as drug availability and cost. ${ }^{3}$ The Asian HAP guidelines ${ }^{3}$ place particular emphasis on consideration of local microbiology and resistance patterns, on the basis that these patterns vary to a greater degree than in the US and Europe. This logic also applies to the treatment of HAP/VAP/HCAP in a Latin American setting. ${ }^{2}$

Quantitative cultures of lower respiratory secretions (endotracheal aspirates, bronchoalveolar lavage or protected specimen brush specimens collected with or without a bronchoscope) can be used to define both the presence of pneumonia and the etiologic pathogen. ${ }^{1}$ Where possible, quantitative cultures should be obtained before administration of antibiotics. ${ }^{1}$ Empiric therapy should be focused or narrowed on the basis of clinical response (Days 2 and 3 ), and results from diagnostic testing on lower respiratory tract secretions. ${ }^{1,3}$ Late-onset HAP/VAP (5 days or more

Table 2. Summary of guidelines for the management of adults with HAP and VAP (ATS/IDSA) ${ }^{1}$

Where possible, collect lower respiratory tract culture from all patients before antibiotic therapy.

Prescribe early, appropriate, intravenous antibiotic therapy, dependent on MDR risk factors and local resistance patterns.

In empiric therapy, include agents from a different antibiotic class to those already received.

Ceftriaxone, levofloxacin, moxifloxacin, ciprofloxacin, ampicillin/sulbactam or ertapenem are recommended for initial empiric therapy for MRSA infections, with no known risk factors for MDR.

Patients with HCAP require therapy for MDR pathogens.

Linezolid or vancomycin are recommended for initial empiric therapy for MRSA infections with late-onset disease or risk factors for MDR.

Aerosolized antibiotics are useful as adjunctive therapy in VAP due to some MDR pathogens.

Consider de-escalation of antibiotics, depending on lower respiratory tract cultures and clinical response.

Use a shorter duration of antibiotic therapy (7 to 8 days) for patients with uncomplicated HAP, VAP or HCAP showing a good clinical response. 
after hospitalization) is more likely to be caused by MDR pathogens and requires broad spectrum therapy, ${ }^{1,3}$ while early-onset pneumonia can initially be treated with a more limited spectrum antibiotic therapy. ${ }^{1}$

Failure rates of $40 \%$ have been reported and attributed to an inadequate duration of therapy of less than 21 days. ${ }^{58}$ Duration of therapy should be based on careful follow-up for resolution of signs and symptoms of infection, in patients with primary pulmonary infection with cavitary disease or empyema. Experts have recommended 8-14 days of therapy for pneumonia with rapid resolution of symptoms and chest roentgenographic findings. ${ }^{1,4}$ However, Chastre et al. demonstrated that there was no difference in mortality at 28 or 60 days, or in-hospital mortality, between VAP patients receiving appropriate antimicrobial therapy for either 8 days or 15 days..$^{59}$ All bacteremic patients should be carefully assessed for metastatic infections that might require longer treatment or surgical intervention.

Bacteremia and catheter-associated infections

The Infectious Diseases Society of America has provided guidelines for the management of IV catheter-related infections. ${ }^{6}$ Antibiotic therapy for such infections should initially be empiric, with the choice of antibiotics dependant on the severity of the patient's clinical disease, risk factors for infection and the likely pathogens. Vancomycin is traditionally the recommended starting point for suspected MRSA infections.

Bacteremia caused by $S$. aureus can be defined as uncomplicated or complicated. In uncomplicated bacteremia, removal of an obvious source of infection, such as a vascular catheter, is sufficient to resolve the infection, whereas in complicated bacteremia, infection may be persistent even after removal of the catheter due to spread to a remote site, or through the presence of other pathogens. ${ }^{60}$ Removal of vascular catheters of patients infected with S. aureus has been associated with a more rapid response and higher cure rate. ${ }^{6}$ Catheter-associated S. aureus infections do pose a greater risk of endocarditis than bacteremia due to other microbes, so longer treatment (4 weeks or more) may be recommended, even in uncomplicated cases. ${ }^{6}$

\section{Surgical site}

Surgical site infections (SSI) represent the second most common type of healthcare-associated infection. ${ }^{61}$ The most common etiologic cause of SSI is S. aureus. According to data from the Centers for Disease Control and Prevention (CDC), 9-49\% of S. aureus SSIs in the USA from 1992 to 2002 were caused by methicillin-resistant strains. ${ }^{61}$ While surgical opening of the incision, removal of necrotic tissue and drainage of pus is the primary aspect of therapy, accompanying antibiotic therapy is important. Postoperative patients with a temperature higher than $38.5^{\circ} \mathrm{C}$ or a heart rate above 110 beats/min generally require antibiotic treatment. ${ }^{5}$ The choice of antimicrobial agent, as well as the duration of treatment, should be influenced by the location and severity of the infection. ${ }^{61}$ The traditional treatment for MRSA SSI is vancomycin, ${ }^{62}$ although other agents including linezolid, daptomycin and tigecycline represent alternative treatments. ${ }^{61}$

\section{Bone and joint}

Guidelines for the management of bone and joint infections due to methicillin-resistant staphylococci have been developed by Fundación del Centro de Estudios Infectológicos (FUNCEI) in Argentina, ${ }^{63}$ focusing on the treatment of:

- Chronic osteomyelitis (COM): Initial management of MRSA infections should consist of IV administration of glycopeptides, such as vancomycin and teicoplanin. Whenever possible, a combination of antimicrobials should be used (especially in the presence of an implant); glycopeptides can be accompanied by rifampicin, TMP-SMX, minocycline, fusidic acid or clindamycin, according to susceptibility testing. Treatment for 6-8 weeks after the last surgery is appropriate to avoid recurrences. Surgical treatment generally involves excision around the devitalized bone, scars and necrotic tissue, and repair of soft tissue.

- Post-procedure septic arthritis (PPSA): A combination of clinical, surgical and physiotherapy approaches is recommended. Antibiotic treatment for 6-8 weeks post-procedure is considered appropriate; generally $2-4$ weeks parenteral treatment, including a glycopeptide, should precede oral therapy. Surgical treatment should consist of drainage, debridement and removal of fibrinous material, flanges and synechiae, plus abundant flushing of the affected articulation.

- Infections associated with prosthetic joints (PJ): Antibiotic treatment with a glycopeptide should be followed as per guidelines for the treatment of COM and PPSA, for 3-6 months. If necessary, this should be followed by chronic suppressive treatment. Surgical treatment should depend on the PJ's functionality. Cleansing of the implant within 5 days and no later than 2 weeks after symptom presentation should follow an early or late postoperative infection with a "functioning" PJ. With a "nonfunctioning" PJ and postoperative infection, surgical removal and repositioning of a new prosthesis should be considered. Alternative treatments are arthrodesis (external or internal) and amputation (very rarely).

\section{ANTIBIOTIC TREATMENT OF COMMUNITY- ACQUIRED MRSA INFECTIONS}

\section{Pneumonia (CAP)}

Clinical risk factors for S. aureus CAP include end-stage renal disease, injection drug abuse, prior influenza and prior antibiotic therapy (especially with fluoroquinolones) ${ }^{64} \mathrm{CA}$ - 
MRSA should be considered as a possible etiologic agent of CAP, even in an afebrile patient with a normal whiteblood-cell count and without hemoptysis. This is especially true if the patient does not respond appropriately to initial management. The PVL virulence factor has been implicated as the key feature of CA-MRSA, making the associated pneumonia more aggressive, necrotizing and fatal than that caused by methicillin-sensitive S. aureus (MSSA). For treatment of CAP in adults, ATS-IDSA guidelines comment that the most effective therapy has yet to be determined, but they recommend addition of vancomycin or linezolid to empiric treatment when CA-MRSA is a concern. ${ }^{4}$ Traditional 7- to 14-day duration of treatment is recommended. ${ }^{4}$

\section{Skin and soft tissue infections}

Skin and soft tissue infections (SSTI) represent the majority of community-acquired MRSA infections. The first reports of MRSA SSTIs in individuals in the community without predisposing risk factors occurred in the late 1990s. This marked a change in the epidemiology of this pathogen, its relation to other community pathogens, MSSA and interactions with MRSA nosocomial infections. ${ }^{65-68}$ The clinical picture includes a large proportion of abscesses (50-75\%) and cases of cellulitis (25-50\%). However, CA-MRSA has also caused necrotizing fasciitis. ${ }^{69}$ In patients with diabetes, foot infections involving CA-MRSA are a common cause of hospitalization and antibiotic treatment. ${ }^{70}$ The presence of new virulence factors, such as PVL production, has been found in severe forms of CA-MRSA SSTIs worldwide..$^{7-73}$ Therefore, while many MRSA SSTIs are effectively treated in the outpatient setting, more severe forms of CA-MRSA are emerging. The treatment of CA-MRSA SSTIs is also associated with more treatment failures and worse outcomes than CA-MSSA SSTIs. ${ }^{74}$ Infections involving MRSA also lead to greater healthcare costs than MSSA infections. ${ }^{75}$ These severe infections will become more difficult and expensive to treat as their prevalence increases, largely due to increased healthcare costs associated with longer duration of hospitalization. ${ }^{75}$

Most infections caused by MSSA or MRSA are not associated with systemic signs of infection. However, some MRSA SSTIs present with signs and symptoms of a severe, invasive infection, requiring a more aggressive approach. Clinically, patients show signs and symptoms of systemic inflammatory response syndrome (SIRS). These cases demand a preliminary laboratory work-up of blood cultures and a complete blood count, including differential count.

The presence of lesions requiring surgical drainage, areas with severe pain, bullae, skin hemorrhage or sloughing, skin anesthesia and the presence of gas in the tissues, will usually herald the need for hospitalization..$^{5,76}$ Lesions that rapidly increase in size and the appearance of tissue necrosis are particularly ominous signs, and demand vigorous antibiotic coverage and extensive debridement. ${ }^{5}$
Patients can also develop hypotension, generalized skin manifestations or diarrhea, raising suspicion of a communityacquired SSTI due to a toxin-producing strain of MRSA. These manifestations may result from MRSA virulence factors such as PVL, toxic shock syndrome toxin 1 or enterotoxins. ${ }^{77}$

Guidelines for the diagnosis and management of SSTIs ${ }^{5,9}$ provide recommendations for antibiotic choice, dose and duration of treatment for SSTI infections. For severe (complicated) SSTIs, it is recommended that "the clinician should assume that the organism is resistant because of the high prevalence of CA-MRSA strains, and agents effective against MRSA (i.e. vancomycin, linezolid or daptomycin) should be used. Step-down to treatment with other agents for MRSA infection, such as tetracycline or TMP-SMX, may be possible, based on results of susceptibility tests and after an initial clinical response". ${ }^{5}$ The UK guidelines for the management of MRSA infections in the community also recommend teicoplanin as an alternative empiric agent, or tigecycline to provide broader polymicrobial cover if required. ${ }^{9}$

\section{CONCLUSION}

Long-term, successful management of MRSA infections requires a highly coordinated approach, which includes constant surveillance of developing MRSA antibiotic resistance patterns, the development of new therapies and clear, up-todate treatment guidelines. While detailed guidelines are available worldwide for the treatment of various MRSA infections, they are not always used consistently or appropriately. ${ }^{13}$

In Latin America, as in all regions of the world, it is imperative that treatment guidelines are written and adapted in light of regional epidemiology and local medical practice. In addition, the importance of medical officers working as a team to manage MRSA infections cannot be understated. Institutions should establish infection control teams comprising clinicians, microbiologists, infectious disease specialists, pharmacists and nurses ${ }^{78}$ to communicate a clear understanding of local epidemiology and appropriate guidelines.

\section{ACKNOWLEDGEMENTS}

\section{Financial support}

Pfizer Inc., New York, NY, USA, provided support for meetings of the Latin American Working Group on Gram Positive Resistance. Pfizer Inc. had no involvement in the collection, analysis and interpretation of data, in the writing of the manuscripts, or in the decision to submit the articles for publication.

\section{Manuscript preparation}

The support provided by Choice Pharma (Hitchin, UK), funded by Pfizer Inc., consisted of manuscript formatting and writing assistance. 


\section{DISCLOSURES}

C.M. Luna: Advisory Board member for Pfizer, Bayer and Wyeth; consultant for Pfizer; speaker for AstraZeneca.

E. Rodríguez-Noriega: Advisory Board member for Pfizer; consultant for Pfizer, Wyeth, Johnson \& Johnson and Novartis; received research grants from Pfizer, Wyeth, Johnson \& Johnson, Schering-Plough and Cerexa.

L. Bavestrello: Advisory Board member and consultant for Pfizer.

E. Gotuzzo: Advisory Board member and consultant for Pfizer; received research grants from Merck, Sharp \& Dohme; and TIBOTEC consultant for Sanofi Pasteur.

\section{REFERENCES}

1. American Thoracic Society and Infectious Diseases Society of America. Guidelines for the management of adults with hospital-acquired, ventilator-associated, and healthcare-associated pneumonia. Am J Respir Crit Care Med. 2005; 171(4):388-416.

2. Luna CM, Monteverde A, Rodriguez A et al. Clinical guidelines for the treatment of nosocomial pneumonia in Latin America: an interdisciplinary consensus document. Recommendations of the Latin American Thoracic Society. Arch Bronconeumol. 2005; 41(8):439-56.

3. Song JH. Treatment recommendations of hospital-acquired pneumonia in Asian countries: first consensus report by the Asian HAP Working Group. Am J Infect Control. 2008; 36(4 Suppl):S83-92.

4. Mandell LA, Wunderink RG, Anzueto A et al. Infectious Diseases Society of America/American Thoracic Society consensus guidelines on the management of community-acquired pneumonia in adults. Clin Infect Dis. 2007; 44(Suppl 2):S2772.

5. Stevens DL, Bisno AL, Chambers HF et al. Practice guidelines for the diagnosis and management of skin and soft-tissue infections. Clin Infect Dis. 2005; 41(10):1373-406.

6. Mermel LA, Farr BM, Sherertz RJ et al. Guidelines for the management of intravascular catheter-related infections. J Intraven Nurs. 2001; 24(3):180-205.

7. Stein GE, Craig WA. Tigecycline: a critical analysis. Clin Infect Dis. 2006; 43(4):518-24.

8. Gemmell CG, Edwards DI, Fraise AP et al. Guidelines for the prophylaxis and treatment of methicillin-resistant Staphylococcus aureus (MRSA) infections in the UK. J Antimicrob Chemother. 2006; 57(4):589-608.

9. Nathwani D, Morgan M, Masterton RG et al. Guidelines for UK practice for the diagnosis and management of methicillin-resistant Staphylococcus aureus (MRSA) infections presenting in the community. J Antimicrob Chemother. 2008; 61(5):976-94.

10. Siegel JD, Rhinehart E, Jackson M, Chiarello L. Management of multidrug-resistant organisms in health care settings, 2006. Am J Infect Control. 2007; 35(10 Suppl 2):S165-93.

11. Deresinski S. Principles of antibiotic therapy in severe infections: optimizing the therapeutic approach by use of laboratory and clinical data. Clin Infect Dis. 2007; 45(Suppl 3):S177-83.

12. Kollef MH, Sherman G, Ward S, Fraser VJ. Inadequate antimicrobial treatment of infections: a risk factor for hospital mortality among critically ill patients. Chest. 1999; 115(2):462-74.
13. Baudel JL, Tankovic J, Carrat F et al. Does nonadherence to local recommendations for empirical antibiotic therapy on admission to the intensive care unit have an impact on inhospital mortality? Ther Clin Risk Manag. 2009; 5(3):491-8.

14. Kollef MH. Inadequate antimicrobial treatment: an important determinant of outcome for hospitalized patients. Clin Infect Dis. 2000; 31(Suppl 4):S131-8.

15. Farrington M. Infection control education: how to make an impact-tools for the job. J Hosp Infect. 2007; 65(Suppl 2):128-32.

16. Sader HS, Moet GJ, Jones RN. Antimicrobial resistance among Gram-positive bacteria isolated in Latin American hospitals. J Chemother. 2009; 21(6):611-20.

17. Robicsek A, Beaumont JL, Thomson RB, Jr. et al. Topical therapy for methicillin-resistant Staphylococcus aureus colonization: impact on infection risk. Infect Control Hosp Epidemiol. 2009; 30(7):623-32.

18. Shittu AO, Udo EE, Lin J. Phenotypic and molecular characterization of Staphylococcus aureus isolates expressing low- and high-level mupirocin resistance in Nigeria and South Africa. BMC Infect Dis. 2009; 9:10.

19. Hyun DY, Mason EO, Forbes A, Kaplan SL. Trimethoprim-sulfamethoxazole or clindamycin for treatment of communityacquired methicillin-resistant Staphylococcus aureus skin and soft tissue infections. Pediatr Infect Dis J. 2009; 28(1):57-9.

20. Moran GJ, Krishnadasan A, Gorwitz RJ et al. Methicillin-resistant $S$. aureus infections among patients in the emergency department. N Engl J Med. 2006; 355(7):666-74.

21. Szumowski JD, Cohen DE, Kanaya F, Mayer KH. Treatment and outcomes of infections by methicillin-resistant Staphylococcus aureus at an ambulatory clinic. Antimicrob Agents Chemother. 2007; 51(2):423-8.

22. Pappas G, Athanasoulia AP, Matthaiou DK, Falagas ME. Trimethoprim-sulfamethoxazole for methicillin-resistant Staphylococcus aureus: a forgotten alternative? J Chemother. 2009; 21(2):115-26.

23. Ruhe JJ, Menon A. Tetracyclines as an oral treatment option for patients with community onset skin and soft tissue infections caused by methicillin-resistant Staphylococcus aureus. Antimicrob Agents Chemother. 2007; 51(9):3298-303.

24. Forrest GN, Tamura K. Rifampin combination therapy for nonmycobacterial infections. Clin Microbiol Rev. 2010; 23(1):14-34.

25. Perlroth J, Kuo M, Tan J et al. Adjunctive use of rifampin for the treatment of Staphylococcus aureus infections: a systematic review of the literature. Arch Intern Med. 2008; 168(8):805-19.

26. Stevens DL, Gibbons AE, Bergstrom R, Winn V. The Eagle effect revisited: efficacy of clindamycin, erythromycin, and penicillin in the treatment of streptococcal myositis. J Infect Dis. $1988 ; 158(1): 23-8$.

27. Martinez-Aguilar G, Hammerman WA, Mason EO, Jr., Kaplan SL. Clindamycin treatment of invasive infections caused by community-acquired, methicillin-resistant and methicillinsusceptible Staphylococcus aureus in children. Pediatr Infect Dis J. 2003; 22(7):593-8.

28. Gemmell CG. Antibiotics and the expression of staphylococcal virulence. J Antimicrob Chemother. 1995; 36(2):283-91.

29. Lewis JS, 2nd, Jorgensen JH. Inducible clindamycin resistance in Staphylococci: should clinicians and microbiologists be concerned? Clin Infect Dis. 2005; 40(2):280-5.

30. Fiebelkorn KR, Crawford SA, McElmeel ML, Jorgensen JH. Practical disk diffusion method for detection of inducible clindamycin resistance in Staphylococcus aureus and coagulasenegative staphylococci. J Clin Microbiol. 2003; 41(10):4740-4. 
31. Weigelt J, Itani K, Stevens D et al. Linezolid versus vancomycin in treatment of complicated skin and soft tissue infections. Antimicrob Agents Chemother. 2005; 49(6):2260-6.

32. Moellering RC. Linezolid: the first oxazolidinone antimicrobial. Ann Intern Med. 2003; 138(2):135-42.

33. Stein GE, Wells EM. The importance of tissue penetration in achieving successful antimicrobial treatment of nosocomial pneumonia and complicated skin and soft-tissue infections caused by methicillin-resistant Staphylococcus aureus: vancomycin and linezolid. Curr Med Res Opin. 2010; 26(3):571-88.

34. Jones RN. Microbiological features of vancomycin in the 21 st century: minimum inhibitory concentration creep, bactericidal/static activity, and applied breakpoints to predict clinical outcomes or detect resistant strains. Clin Infect Dis. 2006; 42(Suppl 1):S13-24.

35. Hiramatsu K, Hanaki H, Ino T et al. Methicillin-resistant Staphylococcus aureus clinical strain with reduced vancomycin susceptibility. J Antimicrob Chemother. 1997; 40(1):135-6.

36. Smith TL, Pearson ML, Wilcox KR et al. Emergence of vancomycin resistance in Staphylococcus aureus. Glycopeptide-Intermediate Staphylococcus aureus Working Group. N Engl J Med. 1999; 340(7):493-501.

37. Sieradzki K, Roberts RB, Haber SW, Tomasz A. The development of vancomycin resistance in a patient with methicillinresistant Staphylococcus aureus infection. N Engl J Med. 1999; 340(7):517-23.

38. Tenover FC, Weigel LM, Appelbaum PC et al. Vancomycinresistant Staphylococcus aureus isolate from a patient in Pennsylvania. Antimicrob Agents Chemother. 2004; 48(1):275-80.

39. Chang S, Sievert DM, Hageman JC et al. Infection with vancomycin-resistant Staphylococcus aureus containing the vanA resistance gene. N Engl J Med. 2003; 348(14):1342-7.

40. Moise-Broder PA, Sakoulas G, Eliopoulos GM et al. Accessory gene regulator group II polymorphism in methicillin-resistant Staphylococcus aureus is predictive of failure of vancomycin therapy. Clin Infect Dis. 2004; 38(12):1700-5.

41. Lodise TP, Miller CD, Graves J et al. Predictors of high vancomycin MIC values among patients with methicillin-resistant Staphylococcus aureus bacteraemia. J Antimicrob Chemother. 2008; 62(5):1138-41.

42. Kollef MH. Limitations of vancomycin in the management of resistant staphylococcal infections. Clin Infect Dis. 2007; 45(Suppl 3):S191-5.

43. Rybak MJ, Lomaestro BM, Rotscahfer JC et al. Vancomycin therapeutic guidelines: a summary of consensus recommendations from the infectious diseases Society of America, the American Society of Health-System Pharmacists, and the Society of Infectious Diseases Pharmacists. Clin Infect Dis. 2009; 49(3):325-7.

44. Schaison G, Graninger W, Bouza E. Teicoplanin in the treatment of serious infection. J Chemother. 2000; 12(Suppl 5):26-33.

45. Polk RE. Anaphylactoid reactions to glycopeptide antibiotics. J Antimicrob Chemother. 1991; 27(Suppl B):17-29.

46. Babinchak T, Ellis-Grosse E, Dartois N et al. The efficacy and safety of tigecycline for the treatment of complicated intra-abdominal infections: analysis of pooled clinical trial data. Clin Infect Dis. 2005; 41(Suppl 5):S354-67.

47. McAleese F, Murphy E, Babinchak T et al. Use of ribotyping to retrospectively identify methicillin-resistant Staphylococcus aureus isolates from phase 3 clinical trials for tigecycline that are genotypically related to community-associated isolates. Antimicrob Agents Chemother. 2005; 49(11):4521-9.
48. Rodvold KA, Gotfried MH, Cwik M et al. Serum, tissue and body fluid concentrations of tigecycline after a single $100 \mathrm{mg}$ dose. J Antimicrob Chemother. 2006; 58(6):1221-9.

49. Boucher HW, Sakoulas G. Perspectives on Daptomycin resistance, with emphasis on resistance in Staphylococcus aureus. Clin Infect Dis. 2007; 45(5):601-8.

50. Arbeit RD, Maki D, Tally FP et al. The safety and efficacy of daptomycin for the treatment of complicated skin and skinstructure infections. Clin Infect Dis. 2004; 38(12):1673-81.

51. Silverman JA, Mortin LI, Vanpraagh AD et al. Inhibition of daptomycin by pulmonary surfactant: in vitro modeling and clinical impact. J Infect Dis. 2005; 191(12):2149-52.

52. Torralba MD, Frey SE, Lagging LM. Treatment of methicillinresistant Staphylococcus aureus infection with quinupristin/ dalfopristin. Clin Infect Dis. 1995; 21(2):460-1.

53. Drew RH, Perfect JR, Srinath L et al. Treatment of methicillinresistant Staphylococcus aureus infections with quinupristindalfopristin in patients intolerant of or failing prior therapy. For the Synercid Emergency-Use Study Group. J Antimicrob Chemother. 2000; 46(5):775-84.

54. Eliopoulos GM. Quinupristin-dalfopristin and linezolid: evidence and opinion. Clin Infect Dis. 2003; 36(4):473-81.

55. Chambers HF, Hegde SS. Combating the growing problem of methicillin-resistant Staphylococcus aureus: do the newer antibiotics represent a better alternative to vancomycin? Expert Rev Anti Infect Ther. 2007; 5(3):333-5.

56. Sopena N, Sabria M. Multicenter study of hospital-acquired pneumonia in non-ICU patients. Chest. 2005; 127(1):213-9.

57. Rotstein C, Evans G, Born A et al. Clinical practice guidelines for hospital-acquired pneumonia and ventilator-associated pneumonia in adults. Can J Infect Dis Med Microbiol. 2008; 19(1):19-53.

58. Moise PA, Schentag JJ. Vancomycin treatment failures in Staphylococcus aureus lower respiratory tract infections. Int J Antimicrob Agents. 2000; 16(Suppl 1):S31-4.

59. Chastre J, Wolff M, Fagon JY et al. Comparison of 8 vs 15 days of antibiotic therapy for ventilator-associated pneumonia in adults: a randomized trial. JAMA. 2003; 290(19):2588-98.

60. Corey GR. Staphylococcus aureus bloodstream infections: definitions and treatment. Clin Infect Dis. 2009; 48(Suppl 4):S254-9.

61. Anderson DJ, Kaye KS. Staphylococcal surgical site infections. Infect Dis Clin North Am. 2009; 23(1):53-72.

62. Stevens DL, Herr D, Lampiris $\mathrm{H}$ et al. Linezolid versus vancomycin for the treatment of methicillin-resistant Staphylococcus aureus infections. Clin Infect Dis. 2002; 34(11):1481-90.

63. Stamboulian D, Di Stefano C, Nacinovich F et al. Guidelines for the management of bone and joint infections due to methicillin resistant staphylococci. Medicina (B Aires). 2002; 62(Suppl 2):5-24.

64. Mandell LA. Antimicrobial resistance and treatment of community-acquired pneumonia. Clin Chest Med. 2005; 26(1):57-64.

65. Boucher HW, Corey GR. Epidemiology of methicillin-resistant Staphylococcus aureus. Clin Infect Dis. 2008; 46(Suppl 5):S3449.

66. Chambers HF. The changing epidemiology of Staphylococcus aureus? Emerg Infect Dis. 2001; 7(2):178-82.

67. Gorak EJ, Yamada SM, Brown JD. Community-acquired methicillin-resistant Staphylococcus aureus in hospitalized adults and children without known risk factors. Clin Infect Dis. 1999; 29(4):797-800.

68. Herold BC, Immergluck LC, Maranan MC et al. Communityacquired methicillin-resistant Staphylococcus aureus in children with no identified predisposing risk. JAMA. 1998; 279(8):593-8. 
69. Miller LG, Perdreau-Remington F, Rieg G et al. Necrotizing fasciitis caused by community-associated methicillin-resistant Staphylococcus aureus in Los Angeles. N Engl J Med. 2005; 352(14):1445-53.

70. Lipsky BA, Berendt AR, Deery HG et al. Diagnosis and treatment of diabetic foot infections. Clin Infect Dis. 2004; 39(7):885-910.

71. Diep BA, Sensabaugh GF, Somboona NS et al. Widespread skin and soft-tissue infections due to two methicillin-resistant Staphylococcus aureus strains harboring the genes for PantonValentine leucocidin. J Clin Microbiol. 2004; 42(5):2080-4.

72. Vandenesch F, Naimi T, Enright MC et al. Community-acquired methicillin-resistant Staphylococcus aureus carrying Panton-Valentine leukocidin genes: worldwide emergence. Emerg Infect Dis. 2003; 9(8):978-84.

73. Rodríguez-Noriega E, Seas C, Guzmán-Blanco M et al. Evolution of methicillin-resistant Staphylococcus aureus clones in Latin America. Int J Infect Dis. 2010; 14:e560-6.
74. Davis SL, Perri MB, Donabedian SM et al. Epidemiology and outcomes of community-associated methicillin-resistant Staphylococcus aureus infection. J Clin Microbiol. 2007; 45(6):1705-11.

75. Shorr AF. Epidemiology and economic impact of meticillinresistant Staphylococcus aureus: review and analysis of the literature. Pharmacoeconomics. 2007; 25(9):751-68.

76. Wong $\mathrm{CH}$, Khin LW, Heng KS et al. The LRINEC (Laboratory Risk Indicator for Necrotizing Fasciitis) score: a tool for distinguishing necrotizing fasciitis from other soft tissue infections. Crit Care Med. 2004; 32(7):1535-41.

77. Diep BA, Carleton HA, Chang RF et al. Roles of 34 virulence genes in the evolution of hospital- and community-associated strains of methicillin-resistant Staphylococcus aureus. J Infect Dis. 2006; 193(11):1495-503.

78. Gordts B. Models for the organisation of hospital infection control and prevention programmes. Clin Microbiol Infect. 2005; 11(Suppl 1):19-23. 